\section{A convergência tecnológica}

\section{RESUMO}

0 presente texto aborda a questão da explosão e ubiqüidade das tecnologias, sobretudo aquelas próprias ao mundo da comunicação e suas inevitáveis possibilidades de convergências. Foca a inescapável necessidade de melhor conhecimento, maior domínio e compreensão para o pleno uso de suas potencialidades e aplicações, uma vez que são formatadas visando à interoperabilidade. $\mathrm{O}$ advento da tecnologia digital trouxe novas denominações, fazendo com que se conviva com universo diferenciado de vocábulos. No mundo atual, só parte da população tem acesso aos bens do ciberespaço, demonstrando que o maior esforço deve ser o de achar condições para os que não têm acesso. Todavia, o maior intento parece ser 0 da produção de conteúdos num mundo totalmente midiatizado.

\section{ABSTRACT}

This text aims the question of the explosion and ubiquity of the technologies mainly those concerned to the communication field and their inherent possibilities of convergence. It focus the strong necessity of better knowledge, domain and comprehension looking at the plein use of its potentialities and applications, since those are planned with interoperability. The arrival of the digital technology brought new terms and vocabulary. Only part of the society has access to the goods of the cyberspace showing that the biggest work shall be that of finding conditions of changing that. However, the major task looks like being the race for content in a word absolutely dominated by the media.

\section{PALAVRAS-CHAVE (KEY WORDS)}

- Convergência (Convergence)

- Tecnologia (Technology)

- Comunicações (Communication)

\section{Sebastião Carlos de Morais Squirra}

NO MUNDO TECNOLÓGICO sem fronteiras, um dos mais freqüentes sentidos do modismo digital tem sido a constante e genérica aplicação do conceito de convergência. Este termo - originário e típico da área da matemática - foi em certo momento importado por alguns cientistas sociais e usado como demonstração de certo "iluminismo" teórico para justificar alguns fenômenos que sinalizavam que, de fato, a vida em sociedade mudava e o que se precisava focalizar eram as confluências tecnológicas que então surgiam a todo galope.

A convergência tecnológica deve ser entendida como a chegada de um vasto cenário de instrumentos sobretudo digitais que desempenham - ou podem desempenhar - funções técnicas assemelhadas ou complementares. Nascida na área tecnológica, logo recebeu amplitude com o linguajar deslumbrado e futurista dos tecnólogos comunicacionais e das empresas midiáticas. Encontra-se hoje razoavelmente assimilada nos distintos cenários científicos e comerciais pela concordância de que as tecnologias - sobretudo as da comunicação devem se enxergar, possibilitar conexões e acoplagens e trocar dados entre si, permitindo que os consumidores tenham pleno e fácil acesso aos enlaces digitais que passaram a ser disponibilizados. É entendida como a integração tecnológica em uma base comum, uma vez que apesar das formas da tecnologia serem diferentes, elas permitem um princípio básico que é a comunicação direta de um usuário com outro através de um conjunto invisível de conexões e sistemas de aberturas, interpretações e disponibilização de dados. Assim, possibilitam trocas de gigantescos volumes de informação a partir de grande conjunto de interfaces que permitem o acesso à informação em tempo real e/ou aquela estocada nos circuitos informatizados dos equipamentos digitais.

Apesar de reconhecer que os proces- 
sos de trocas de informação entre os distintos equipamentos e plataformas digitais estão muito mais "amigáveis" hoje que anos atrás, resta indagar o que deverá acontecer com os cidadãos comuns que se encontram irreversivelmente alijados do "olho do furacão" tecnológico que se experimenta nos dias atuais? É importante destacar a pouco provável possibilidade de que se possa fazer opção por estar inserido ou não no "cimento tecnológico" que se constitui a experiência comunicacional contemporânea diária. Isto, quer seja pelos constantes apelos pela contínua adesão aos utensílios com a mais recente capacidade tecnológica "on board", quer seja pela inevitável constatação de que o entorno que rodeia sobretudo os seres metropolizados se encontra fortemente equipado com os "gadgets" do melhor que a indústria globalizada vem produzindo em ritmo feérico de criação de novas características, e de substituição das anteriores. Quer dizer, os apelos mercadológicos atingem indistintamente a todos, habilitados - ou não -, convencidos - ou não -, os que têm recursos financeiros folgados ou não - etc.

Uma concreta manifestação do desafio pela infindável atualização de conhecimentos (trazendo o princípio do "life-long-learning") que nos afeta constantemente é a constatação de que hoje os seres "inseridos no sistema" devem conquistar domínio distinto de habilidades e cultura tecnologizada se quiserem concorrer e/ou desfrutar das facilidades da vida moderna. Mas isto requer mudanças de comportamento para a ampliação dos universos de domínio e ação, além de disposição para o treinamento visando à absorção de novos conceitos e competências. Nesse sentido, aqueles que não se interessam pela atualização tecnológica correm sério risco de alguma forma de "exclusão digital". Todavia, mesmo aqueles que diuturnamente correm para entender o que a indústria produz podem levar choques com o que se deparam. Mas, antes dos equipamentos em si, as barreiras podem mesmo emergir, por exemplo, no en- frentamento do que significam os vocábulos que definem as aplicações. Afinal, o que tecnopolis, realidade virtual, tecnologia da informação, waap, FTP, gopher, ciberespaço, educação a distância, wired cities, URL, LAN, cibersexo, usenet, carros inteligentes, MUD, ciberesfera realmente querem dizer? E aqui, vale uma constatação nada comodista: acrônimos e denominações novos estão sendo contínua e incessantemente forjados. Estes e aqueles classificam todos os que querem - ou necessitam - viver no bojo da Era da Informação.

Certa ocasião, constatando a "avalanche" de termos novos que surgia, dediquei-me a anotá-los. Resgato alguns: netizen; teleology; cybercrooks; bandwitch; electric drivers license; cybercapitalists; cybercultists; digital paper; edutainment; mediaspace; e-learning; teledemocracy; cyberculture; cyberlife; cyberia; netyquette; cybersociety; infowritter; conectividade; ebook; telestaffing; PCMCIA; hypermedia; computopia; augmented reality; infotech; GPS; datawarehouse; liquid information; accessibility; cybertimes; cyberpunk; hyperfiction; ICQ; docupen; playstation; bulletin board system; CAR; telecosm; infotainment; neural network; interatividade; cybernetics; CMC; netbook; MP3; protocolo TCP-IP; cybermedia; usability; interoperability; on-demand publishing; global village; roaming; HTML, telecommuting; cyberpublishing; PDA; interoperability; cyberbeing; teleputer; DVD; cybernomics; infoculture, virtual reality, free software etc. Entendo que, justamente por isso, já na metade dos anos 1990, surgiram os primeiros dicionários para ajudar a compreender melhor esta seara de neologismos. Três dos primeiros, que tive acesso nos EUA, chamavam-se "The Internet Dictionary"1, "The cyberspace lexicon" ${ }^{2}$ e "Atlas to the Word Wide Web"3.

Mais recentemente, outros termos vêm se destacando: wirelless; smartphone; XTML; Bussiness Intelligence; software livre; nanotecnologia; MP3; hot spots; blogs; bluetooth; DVD Blu-ray disc; VoIP; Wi-Fi; 
Terabyte; knowbots; e-forms; UWB-Ultra wideband wirelles technology; WiMAX; 3G; KinoCast; voiceWeb; LBS; redes integradas; interoperabilidade universal; networking; SACD-SuperAudio CD; DVD Audioetc, Open Software. E ainda mais recentemente, surgiram: ICT; S-MBC; T-MBC; Game Cube, TiVo; IP-TV; X-Box etc. Dessa forma, impossível descartá-los se a idéia é inscrever-se - e deleitar-se - no mundo dos "alfabetizados" tecnológicos.

Muito se fala das tecnologias da informação. No cenário dos "portos" e conexões amigáveis, este vem sendo o denominador comum, que separa - sim, já separa - os que "têm dos que não têm acesso" aos bens da sociedade moderna. Confirma-se, de certa forma, nova cizânia social, não se podendo crer em "tecnologia da informação para as massas". Nos Fóruns Econômicos Mundiais realizados em Davos, Suíça, o mais repetido tem sido que "dos seis bilhões de seres no globo, cerca da metade vive com cerca de dois dólares por dia". Quer dizer, além da incapacidade para uma vida minimamente normal em termos de alimentação, moradia etc., pouco mais de 3 bilhões de seres estão também totalmente apeados do acesso, compreensão, uso e domínio desses tipos de recursos (é óbvio que de outros também), fazendo com que, concreta e irrecusavelmente, se esteja focando os seres que sempre tiveram condições culturais e econômicas, estando enlaçados no segmento médio superior e superior da vida organizada.

Por reconhecer isso, um novo termo para designar esta realidade foi cunhado na década de 1990 e fala da "divisão digital" (digital divide). Inicialmente servia para explicar as diferenças econômicas para o acesso às tecnologias da informação e comunicação internamente aos EUA, passando em seguida a significar também o distanciamento que se constatava no mundo, quando a definiram como "divisão digital global" (global digital divide). Assim, como imaginar que volume expressivo de almas terá acesso, e mais complicado, con- seguirá extrair algum benefício dos instrumentos tecnológicos avançados? E não se trata de somente ter os instrumentos em mãos. É fundamental lembrar que o domínio desses recursos requer uma diferenciada forma de cultura e apropriação instrumental. Trata-se de imersão num universo amplo onde, inclusive, conhecimentos de uma língua estrangeira (inevitavelmente, o inglês) são necessários e onde a familiaridade com o instrumento básico - o computador - se configura como questão primária. Portanto, trata-se de cenário no qual só seres alfabetizados tecnologicamente terão alguma chance. Afinal, é impossível digitar algo nas diferentes "portas de entrada" (os teclados) sem saber o que cada código ali inscrito significa. E o que este vai provocar, construindo significados conscientemente dominados ou não. Além disso, outro atributo especial torna-se imprescindível: é preciso certa dose de ação e conceituação abstrata, pois sem isto, como entender o mundo virtual? Pesquisas sobre o mundo das tecnologias avançadas do Departamento de Estado dos EUA descobriram que raça, renda e educação são os determinantes primários quanto ao acesso à internet naquele país. Esta constatação seguramente deverá ser válida para outras nações, inclusive o Brasil.

Voltando ao tema, lembro que a eletricidade, que trouxe consigo os aparelhos de televisão, geladeira e telefone, está presente hoje em boa parte dos lares. Com estes, alguma forma de automação e de tecnologia instalou-se nas últimas décadas em parte do cotidiano das famílias do país, sobretudo as das classes A e B. E isto vem de pouco tempo. Afinal, quantos não se lembram de quando o forno microondas era o "must" do desejo das famílias que almejavam incrustar-se na sociedade moderna, aquela que entendiam ser de enorme bemestar e a do mínimo esforço? Até passado não muito distante, nos aeroportos internacionais do país, as "estrelas" eram o aparelho de videocassete, os fornos microondas e as câmeras de vídeo, distintivos do sonho 
de consumo de boa parte da classe média alta.

Esta "onda" passou e hoje muitos estão convencidos que ela foi substituída pelo mundo da comunicação abundante e disponível na "ponta dos dedos", onde a sobreposição de instrumentais de contato e assimilação de informações eleva a condição da vida, saciando o apetite de renovação do conhecimento e de inserção na sociedade competitiva. A voracidade e a pluralidade de enfoques são tamanhas que em reportagem de capa de 19 de junho de 2000 a revista Time trazia várias questões intrigantes: "Será o cibersexo melhor que o sexo real? A TV que 'emite odor' substituirá a TV normal? Continuaremos a dirigir nossos carros (ou serão os carros que nos dirigirão)? O meu computador tornar-se-á mais inteligente que eu? Será que os robôs ficarão tão independentes que requererão seus direitos? Continuaremos a folhear as páginas dos livros? Será que os cibercriminosos dominarão o mundo?" etc. São todos temas extremamente intrigantes a todos, sejam estudiosos ou simples consumidores. Os textos analisam e fazem previsões de para onde deve caminhar o futuro dos seres e suas relações com a tecnologia. Afinal, muitos querem saber o que a moderna e digital "fluência conjunta" dos dias atuais tem a oferecer e para onde a simbiose tecnológica está nos levando.

Exatamente nesta vertente, algumas obras se destacam. Uma delas é do jornalista e pesquisador Ethevaldo Siqueira que escreveu o excelente livro "2015, Como viveremos"4. Por ter como foco "o futuro, na visão de 50 famosos cientistas e futurologistas do Brasil e do mundo", apresenta panorama extremamente cuidadoso do que virá, na concepção dos atores que estão definindo o caminho tecnológico que seguiremos e na linha de frente das pesquisas na indústria e fora dela. Outra obra de fôlego é a trilogia do professor João Antonio Zuffo "A sociedade e a economia no novo milênio" ${ }^{\prime}$, que no volume I enfoca a Tecnologia e a infossociedade, no II, a Macroeconomia e empregos; e no III, a Infoeconomia. Muitas outras importantes obras e autores poderiam ser citados, mas nos contentaremos, neste momento, com estas.

Além do cidadão comum, é inegável destacar que a tecnologia está facilitando e muito - a vida dos profissionais de várias áreas, especialmente a dos pesquisadores e jornalistas. Esta, de certa maneira, incrementou radicalmente a liberdade de expressão e de investigação. Aliás, os computadores estão sendo usados de forma tão extensiva pelos jornalistas, que atualmente as matérias assim produzidas estão abocanhando ano após ano o Pulitzer Prize, o mais importante prêmio ao trabalho jornalístico nos EUA. Uma pesquisa que realizei revelou que em 1989 o Atlanta Journal and Constitution recebeu o prêmio por uma série de artigos que mostrava o racismo na concessão de empréstimos pelos bancos. No ano seguinte, foi a vez do Minneapolis Star Tribune pelo trabalho jornalístico de descoberta de um esquema de queima intencional de propriedades e que envolvia os próprios bombeiros da cidade de St. Paul. Em 1991, O Indianapolis Star foi o escolhido por uma série de matérias sobre casos de imperícia e maus-tratos médicos no estado. No ano seguinte, o jornal Kansas City Star foi premiado por demonstrar que o Departamento de Agricultura dos EUA estava infestado com fraudes, desperdício de recursos e favoritismo para as poderosas empresas alimentícias do país. O jornal The Miami Herald consagrou-se pela cobertura dos estragos do furacão Andrews, em 1993, demonstrando como várias construtoras burlaram o código de construção civil, o que contribuiu bastante para aumentar o volume dos estragos. Em 1994, foi a vez do jornal Akron Beacon Journal por uma série sobre racismo. E por aí vai. No Brasil, alguns comunicadores e órgãos de imprensa trilham o mesmo caminho. Mas, e na vida pessoal, o que vai acontecer?

É seguro que tudo deve passar pela tela de algum tipo de aparelho de televisão (sobretudo as planas, de plasma ou de cris- 
tal). No passado, nos contentávamos com um aparelho (grande, pesado e de tubos catódicos) que, via de regra, ficava na sala de visitas, no ambiente "social" dos lares, onde se celebrava a "comunhão" televisiva. O que já se presencia nos dias atuais indica que será diferente no mundo convergente: viveremos numa profusão de "canais" de acesso aos dados e às informações de todos os tipos, recursos e formatos. Seguindo a tendência do mercado de miniaturização e barateamento contínuos, os consumidores passarão a adquirir específicos equipamentos de conexão e exibição, que estarão alojados nos diversos cômodos das residências e servirão para a leitura dos dados e interação a partir da explicitação das escolhas. Das simples telas inseridas nas portas das geladeiras e armários - que se destinarão ao controle e reposição dos alimentos, mas que também multiplicarão os aparelhos de TV e rádio convencionais -, às telas de 40 ou 60 polegadas, que difundirão dados e programas isoladamente. Estas, quando agrupadas, comporão imenso mosaico semelhante às telas dos cinemas.

Seguramente, as "portas de comunicação" estarão por toda parte, em formatos grandes ou radicalmente discretos, e serão colocadas nas mesas dos escritórios - nas empresas e nos domicílios -, ou ainda, nas paredes dos cômodos domésticos. Mas também nos carros, ônibus coletivos ou em partes dos instrumentos do dia-a-dia das pessoas (relógios, óculos etc.) e mesmo como próteses inseridas no próprio corpo humano. Alguns cientistas advogam que os microfones devem desaparecer, pois poderão ser feitas incrustações dentárias de minúsculos microfones imunes à acidez e umidade da saliva, de forma que as pessoas poderão atender e falar ao telefone celular, por exemplo, sem precisar se dirigir ao microfone do aparelho. O mesmo acontecerá com o fone de ouvido ou alto-falante dos equipamentos. Aparelhos semelhantes a brincos ou minúsculos instrumentos colocados dentro do ouvido cumprirão esta tarefa. Nesse sentido, experiências já foram desenvolvidas - e apresentadas publicamente - de colocação de chips em jóias (sobretudo colares) e todo tipo de adorno (relógios, chapéus), tendo sido criado o termo "joalheria cibernética" (cybernetic jewelry) para designar estas possibilidades de "sistemas vestidos" (wearable systems). As facilidades tecnológicas permitirão - aliás, já o fazem - o comando de atividades nestes equipamentos via voz humana, sem a necessidade da inserção mecânica para o atendimento do que se pretende fazer. Tudo isto, sem fios, no melhor da tecnologia Wi-Fi (Wireless Fidelity).

E o que é mais alvissareiro: não mais deveremos assistir à televisão em tempo real. Experiências vêm sendo feitas - aliás, já estão disponíveis! - no sentido de libertar as pessoas do ato de assistir ao telejornal das 8 da noite, às 8 da noite! Aqueles que, por algum motivo, desejarem ver o telejornal às 10 da noite (ou em qualquer outro horário) na sua versão integral, ou em partes editadas de acordo com seu gosto pessoal, poderão programar isto. Afinal, nem todos gostam de política, esportes, moda ou culinária. Neste cenário, os usuários passarão a ficar livres da "camisa-de-força" da programação, que hoje obriga todos a ficar sentados esperando a decisão do programador da rede, que colocou aquele programa naquele horário (muitas vezes, o filme chega com atraso, menosprezando a vontade e a paciência da audiência). Além disso, a "mão única" da emissão - com a formatação unilateral dos seus estilos e conteúdos - não permite a seleção e muito menos a interação com o que está sendo transmitido. Neste mundo de autoritarismo e unidirecionamento programático-televisivos, assiste-se ao que o dono da emissora (e seus setores de marketing) entende ser bom para todos, de forma massificada. No universo tecnológico da máxima convergência, isto não mais atrofiará os desejos já que se antevê amplas possibilidades de pleno atendimento das vontades individualizadas dos usuários.

No intercâmbio sistêmico dos equipa- 
mentos digitais, o que se prenuncia é a oferta crescente de uma extraordinária gama de dispositivos comunicacionais, que trará embutido o máximo de liberdade individual, com o mínimo de esforço, complexidade e custo. Justamente por causa de todas estas características, e apesar de inferir que a chamada "Revolução da informação" provocará transformação profunda nos hábitos sociais, serão recursos que, além de se reconhecerem, serão facilmente amigáveis e compreensíveis para os usuários. Processo semelhante aconteceu, por exemplo, com a chegada do livro, do vapor e da eletricidade, que demoraram longas décadas para terem amplo desfrute. Isto porque inevitavelmente as novidades chegam primeiro àquele segmento social que já se deliciava com a razoável gama de opções de conexão e usufruto dos bens, fruto dos avanços da tecnologia. Do livro eletrônico (e-book) ao controle da banheira, do microondas à iluminação dimerizada, do telefone portátil ao correio digital. E da pré-seleção dos programas favoritos nas emissoras convencionais à gravação de programas "sob encomenda" (NOD-Newson-demand ou VOD-Video-on-demand) aos programas especiais com pré-pagamento (pay-per-view).

Nesta "colcha de retalhos" tecnológica um segmento vem atraindo decididamente a atenção da população: os videogames. Recentemente, foi divulgado que os norteamericanos estavam, inclusive, substituindo seus atos costumeiros (assistir à TV, por exemplo) pela prática do videogame, sendo que volume expressivo de adolescentes está dedicando uma média de sete horas por semana jogando nas teles dos computadores, chegando até a substituir uma das refeições para ficar na frente das telas. Dez por cento dos entrevistados reconheceram que podem ser considerados viciados neste tipo de interatividade, que já supera Hollywood em faturamento.

Por isso, creio que a sociedade (e a pesquisa em geral) vive hoje um momento realmente muito importante, tanto do lado de quem pratica quanto de quem usa os recursos e serviços disponibilizados digitalmente. Em várias instâncias (sobretudo na literatura norte-americana) é freqüente encontrar o uso do termo 'revolucionário' para definir este especial momento que se vivencia. Apesar de reconhecer a extraordinária evolução tecnológica por que passa a sociedade, constato que o termo ainda merece ser aplicado com discrição, pelo fato desta evolução ainda estar "em curso", não tendo ainda alcançado seu "porto" de atracamento. Mas, esta deve ser justamente a diferença com as demais conquistas: os avanços deverão ser contínuos, sem a configuração de uma "reta de chegada".

Independentemente disto e ao trazer o foco para o mundo das profissões, pode-se perceber que mesmo o clássico conceito do que seja jornalismo está no foco de algumas discussões, trazendo uma evidência certa: quem souber se adaptar e usufruir as modernas facilidades de acesso às múltiplas fontes de informação estará na frente e terá sua vida radicalmente simplificada e mais animada. A conjunção tecnológica está preparando o terreno para transmitir TV nos aparelhos celulares. A empresa Nokia está prometendo isso para o segundo semestre do ano que vem, estimando que 125 milhões de consumidores estarão assistindo à TV dessa forma nos próximos cinco anos. E o Protocolo de internet vai mudar a forma como vemos TV, fazendo com que na tela onde hoje assistimos unicamente a programas televisivos gerados na "cabeça da rede", passem a ser visualizados as chamadas telefônicas, e-mails, correio de voz, multicâmeras etc.

Obviamente, isso vai alterar as regras no mundo das profissões, que não é estático e tranqüilo, pois tanto o cidadão comum quanto os comunicadores e os pesquisadores precisarão de outras habilidades, muita persistência e talento. $\mathrm{O}$ que destaco é que o incremento e a diversificação das habilidades tecnológicas ajudarão, com certeza, para que os comunicadores e pesquisadores tornem-se mais pluralistas, acurados, 
eficientes, dinâmicos e universais, usufruindo de todas as possibilidades tecnológicas num cenário que Michael Dertouzos definiu como "a era da unificação", no livro 'O que será' (Companhia das Letras, 1997). Nesta obra, o autor revela seu desejo de confraternização, afirmando que "a nova era da unificação nos reconciliará com a fé, razão, natureza e humanidade, abrindo caminho para a Quarta Revolução, muito adiante dos artefatos humanos e suas conseqüências, voltada para dentro, para a compreensão de nós mesmos". ${ }^{6}$ Aliás, em arroubo saudavelmente otimista, Dertouzos prega ser possível aproximar os 'techies' dos 'humies' ao afirmar que a revolução informática "chegará ao ponto de aproximar as visões polarizadas dos tecnocratas que endeusam o raciocínio científico àquelas dos humanistas que veneram a fé na humanida$\mathrm{de}^{\prime \prime 7}$.

O autor traça paralelo entre as duas revoluções econômicas anteriores, concluindo que "a revolução da informação provocará uma transformação igualmente profunda" ${ }^{8} \mathrm{E}$, neste ponto, revela o estofo central do seu raciocínio: o Mercado da Informação, espaço de busca, comparação, 'negociação' e aquisição que já atinge a maioria dos setores em boa parte do globo. Além do mundo chamado "dos negócios", esse cenário vai, inevitavelmente, envolver os pesquisadores e os cientistas sociais. E, por tabela, a população em seu conjunto.

Quer dizer, os comunicadores devem ficar ainda mais atentos para o universo da tecnologia, pois uma vez superados os estágios de conversão, experimento e domínio, o passo seguinte será o da constituição de amplas narrativas com conteúdos criativos e sedutores. Assim, a próxima batalha será pela democratização do acesso, não por pura tecnologia. E por conteúdo para alimentar as mídias, conforme oportunamente alertou uma edição do Media Studies Journal, que trouxe como título "The race for content". ${ }^{9}$ Estes serão os verdadeiros desafios dos dias à frente .

\section{Notas}

1 CRUMLISH, Christian. The internet dictionary -The essential guide to netspeak. San Francisco: Sybex, 1995.

2 COTTON, Bob e OLIVER, Richard. The cyberspace lexycon. London: Phaidon, 1994.

3 POWELL, Bob e WICKRE, Karen. Atlas to the Word Wide Web. Emeryville: Ziff-Davis Press, 1995.

4 SIQUEIRA, Ethevaldo. 2015 - Como viveremos. São Paulo: Comquest, 2004.

5 ZUFFO, João Antonio. A sociedade e a economia no novo milênio. Barueri: Manole, 2003.

6 DERTOUZOS, Michael. 0 que será. Como o novo mundo da informação transformará nossas vidas. São Paulo: Cia das Letras, 1997, p. 389.

7 idem, p. 26

8 idem, p. 30.

9 The race for content. Media Studies Journal. Volume 8, Number I, Winter 1994. The Freedom Forum Media Studies Center. Nova York, Columbia University, 1994. 